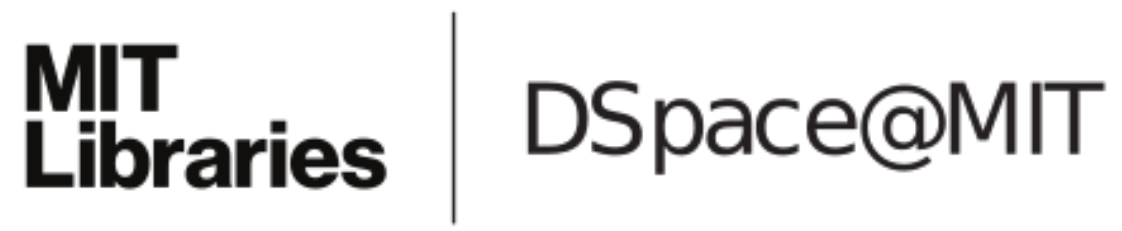

\author{
MIT Open Access Articles
}

\section{Synchrotron radiation $x$-ray absorption fine- structure and Raman studies on CdZnTe ternary alloys}

The MIT Faculty has made this article openly available. Please share how this access benefits you. Your story matters.

Citation: Wu, Yu Li et al. "Synchrotron radiation x-ray absorption fine-structure and Raman studies on CdZnTe ternary alloys." Hard X-Ray, Gamma-Ray, and Neutron Detector Physics XI. Ed. Ralph B. James, Larry A. Franks, \& Arnold Burger. San Diego, CA, USA: SPIE, 2009. 74490Q-11. ( 2009 SPIE--The International Society for Optical Engineering

As Published: http://dx.doi.org/10.1117/12.825823

Publisher: The International Society for Optical Engineering

Persistent URL: http://hdl.handle.net/1721.1/52737

Version: Final published version: final published article, as it appeared in a journal, conference proceedings, or other formally published context

Terms of Use: Article is made available in accordance with the publisher's policy and may be subject to US copyright law. Please refer to the publisher's site for terms of use. 


\title{
Synchrotron Radiation X-ray Absorption Fine-structure and Raman Studies on CdZnTe Ternary Alloys
}

\author{
Yu Li Wu ${ }^{1,}$ Yen-Ting Chen ${ }^{1}$, Zhe Chuan Feng ${ }^{1, *}$, Jyh-Fu Lee $^{2}$, P. Becla ${ }^{3}$, and Weijie Lu $^{4}$ \\ ${ }^{1}$ Graduate Institute of Photonics \& Optoelectronics, and Department of Electrical Engineering, \\ National Taiwan University, Taipei, Taiwan 106-17, ROC \\ ${ }^{2}$ National Synchrotron Radiation Research Center, Hsinchu, 300-76 Taiwan, ROC \\ ${ }^{3}$ Francis Bitter National Magnet Laboratory, Massachusetts Institute of Technology, Cambridge, \\ MA 02139, USA \\ ${ }^{4}$ Department of Chemistry, Fisk University, Nashville, TN 37208, USA \\ * Corresponding author. Tel: 886-2-3366-3543, fax: 886-2-2367-7467, \\ e-mail: fengzc@cc.ee.ntu.edu.tw
}

\begin{abstract}
The synchrotron radiation (SR) X-ray absorption fine-structure spectroscopy (XAFS) technology has been employed to obtained $\mathrm{Zn} \mathrm{K}$-edge absorption spectra for $\mathrm{Cd}_{1-x} \mathrm{Zn}_{x} \mathrm{Te}$ alloy with $\mathrm{x}=0.03,0.10,0.20,0.30,0.40,0.50$ and 1.00. Their Fourier transform spectra were analyzed, which have shown a bimodal distribution of bond lengths, suggesting distortion of the Te sub-lattice, so that the linear interpolation is true only in an approximate sense. Synthetic CdZnTe crystals can be used for the room temperature-based detection of gamma radiation. The radiation detection properties of CZT crystals vary widely. A common defect found in most high-quality CZT crystals is Te secondary phases, often located along grain boundaries. The secondary phases can be both large inclusions $(>50 \mu \mathrm{m})$ and smaller precipitates $(<50 \mu \mathrm{m})$. The Te secondary phases distributed throughout the crystal can cause changes to the detector leakage current, resulting in decreased radiation spectrometer performance. This set of $\mathrm{Cd}_{1-\mathrm{x}} \mathrm{Zn}_{\mathrm{x}} \mathrm{Te}$ crystals were also measured by Raman scattering at room temperature. The two observed peaks at about 125 and $145 \mathrm{~cm}^{-1}$ which can be assigned to Te $\mathrm{A}_{1}$ and $\mathrm{E}$ phonon mode, respectively. The induced damage on the crystal surfaces by Raman laser has been discussed. It is suggested that in the case of highly $\mathrm{Zn}$ doping CdZnTe crystals, the ZnTe bond were broken by laser exposing and then free Te atoms are migrating to these heated areas which cause Te precipitate. Further, the results of the soft X-ray measurements have been also presented and this part of the experimental data needs to do more penetrating analysis in the future.
\end{abstract}

Keywords: CdZnTe, X-ray absorption fine-structure spectroscopy (XAFS), Extended X-ray Absorption Fine-Structure (EXAFS), bond length, Raman scattering, Te precipitates

\section{INTRODUCTION}

II-VI compound semiconductor $\mathrm{Cd}_{1-\mathrm{x}} \mathrm{Zn}_{\mathrm{x}} \mathrm{Te}(\mathrm{CZT})$ is a material of paramount importance due to its excellent optoelectronic properties. It has been investigated for various industrial applications such as far-infrared and radiation detectors [1-3], solar cells [4, 5], photo refractive devices [6], and so on. However, CZT crystals have faced to some problems for their uses in device fabrication due to its low defect formation energy and $\mathrm{Zn}$ segregation problem. The low defect formation energy causes the high defect density [1,7], and $\mathrm{Zn}$ segregation results in the local chemical inhomogeneity [1]. The defects and chemical inhomogeneity are responsible for the deterioration of the optoelectronic properties. Therefore, in the past decades, considerable efforts have been made to produce CZT crystals with high structural perfection. For example, Triboulet et al. and $\mathrm{Li}$ et al. reviewed various growth methods and post-growth treatment techniques for preparing CZT crystals [8-10]. Among them, the vertical Bridgman method is an excellent one to grow high-quality CZT because of its basic suitability and high efficiency [11, 12]. Various characterization techniques have been employed for the investigation of CZT materials, include infrared (IR) transmission imaging,

Hard X-Ray, Gamma-Ray, and Neutron Detector Physics XI, edited by Ralph B. James, Larry A. Franks, Arnold Burger, Proc. of SPIE Vol. 7449, 74490Q - (C) 2009 SPIE · CCC code: 0277-786X/09/\$18 - doi: 10.1117/12.825823 
synchrotron X-ray topography, photoluminescence spectroscopy, and Raman spectroscopy [13-18, 19, 20-23]. All of these methods have been used to test for quality to predict performance of the crystal as a gamma ray detector.

Large localized defects can cause degraded detector performance across the entire detector [13]. In high-quality detectors, small defects are less likely to cause a large loss in performance when a large area of the crystal is being used as the detector. However, when high-spatial-resolution gamma detection is desired even small defects cause a noticeable decrease in performance [14-16, 18-19]. A common defect found in most high-quality CZT crystals is Te secondary phases, often located along grain boundaries $[13,16,19,24,25]$. The secondary phases can be both large inclusions $(>50$ $\mu \mathrm{m})$ and smaller precipitates $(<50 \mu \mathrm{m})$. Tellurium has a relatively small band gap, $0.33 \mathrm{eV}$, when compared with most CZT crystals, $\sim 1.6 \mathrm{eV}[13,26]$. The Te secondary phases (sometimes referred to as precipitates or inclusions) distributed throughout the crystal can cause changes to the detector leakage current, resulting in decreased radiation spectrometer performance $[15,16,19,27]$. However, it is less clear how a large area of surface Te will affect the spectrometer performance.

Here, the local atomic structure and the phonon mode in $\mathrm{Cd}_{1-\mathrm{x}} \mathrm{Zn}_{\mathrm{x}} \mathrm{Te}$ crystals with different composition have been studied by extended X-ray absorption structure (EXAFS) and Raman scattering, respectively. Further, Raman spectroscopy was also used to examine areas of Te secondary phases on the surfaces of the CZT crystals.

\section{EXPERIMENTS}

The $\mathrm{Cd}_{1-\mathrm{x}} \mathrm{Zn}_{\mathrm{x}} \mathrm{Te}$ alloys were made at Massachusetts Institute of Technology. By reacting the 99.9999\%-pure elemental constituents in evacuated and sealed quartz tubes. The sample $\mathrm{x}$ values of $0.005,0.01,0.03,0.1,0.2,0.3,0.4$, $0.5,0.9$ and 1 were obtained from the mass densities. These precast alloys were regrown by directional solidification in a Bridgman-Stockbarger-type crystal-growth furnace. Regrowth occurred at the rate of $1.2 \mathrm{~mm} / \mathrm{h}$ in the furnace adiabatic zone with a temperature gradient of about $15^{\circ} \mathrm{C} / \mathrm{cm}$. The resulting boules were sliced perpendicular to the growth direction. The slices used for infrared and Raman measurements were annealed at $600^{\circ} \mathrm{C}$ in a Cd-saturated atmosphere for about $5 \mathrm{~d}$. Their surfaces were prepared by lapping, mechanical polishing, and etching in bromine-methanol solution.

We performed two times Raman measurements. The first time was performed in early time, were made in the nearbackscattering geometry on the samples held at $80 \mathrm{~K}$. The exiting light came from an $\mathrm{Ar}+$ laser with a focused beam of diameter $<0.3 \mathrm{~mm}$. The scattered light was dispersed by a triple spectrometer and accumulated by an optical multichannel analyzer (OMA), which gave high sensitivity with resolution of $\sim 2 \mathrm{~cm}^{-1}$. The second time was measured at recently. The spectra were recorded by a Jobin-Yvon T64000 triple spectrometer at National Taiwan University, equipped with a liquid-nitrogen-cooled charged-coupled device (CCD) detector at room temperature in the backscattering geometry. A Si sample is used to calibrate the system. The excitation laser source with a wavelength of $532 \mathrm{~nm}$ at a power of $100 \mathrm{~mW}$ was used and the spectral resolution was less than $0.5 \mathrm{~cm}^{-1}$. The spot size of the laser beam was first measured with a micrometer, which is around $1 \mu \mathrm{m}$, and the power across the light spot approximately forms a Gaussion distribution.

$\mathrm{X}$-ray absorption fine-structure (XAFS) spectra were collected for the $\mathrm{Cd}_{1-\mathrm{x}} \mathrm{Zn}_{\mathrm{x}} T$ e samples at $\mathrm{Zn} \mathrm{K}$-edges in $\mathrm{X}$-ray fluorescence yield mode at beamline 17C of the National Synchrotron Radiation Research Center (NSRRC) in Hsinchu, Taiwan. The photon energy for the XAFS covered the range between 9700 and $10700 \mathrm{eV}$. The intensity of the incident $\mathrm{X}$-ray was monitored by a $\mathrm{N}_{2}$-filled ionization chamber and the fluorescence emitted from the sample was measured by an argon-filled Stern-Held-Lytle detector. A Si (111) double-crystal monochromater with a $0.5 \mathrm{~mm}$ entrance slit was used. A filter was inserted between the sample and the detector window to reduce the noise from scattering and to improve the spectrum quality. All measurements were made at room temperature and all X-ray absorption spectra were normalized to $I_{0}$.

\section{RESULT AND DISCUSSION}

\subsection{Extended X-ray absorption fine structure (EXAFS)}

Extended X-ray absorption fine structure (EXAFS) was employed to study the local structure of $\mathrm{Cd}_{1-\mathrm{x}} \mathrm{Zn}_{\mathrm{x}} \mathrm{Te}_{\mathrm{e}}$ bulk materials for $\mathrm{x}=0.01$ to $\mathrm{x}=1.00$ at the $\mathrm{Zn} \mathrm{K}$-edge. The background contribution to the EXAFS spectra were removed using an algorithm (AUTOBK) developed by Newville et al. [28], which minimizes R-space values in low k-space. Replicate EXAFS scans were co-added to improve the signal to noise ratio. Due to numerous diffraction peaks in the $\mathrm{Zn}$ EXAFS spectra, the samples were spun to average out the diffraction peaks in the EXAFS spectra. All EXAFS spectra were collected to $1000 \mathrm{eV}$ beyond the K-edges for Zn. All EXAFS data were analyzed for wave vectors (k) from $3 \AA^{-1}$ 
to $13 \AA^{-1}$. The chi data were $\mathrm{k}^{2}$ weighted as shown in Fig. 1 and Fourier transformed with a hanning window with $d k=$ $0.5 \AA^{-1}$ to yield R-space data. In Fig. 2 simulated EXAFS spectra were also generated, based on the documented crystallographic properties for $\mathrm{Cd}, \mathrm{Zn}$ and Te using ab initio based theory, which involved FEFF 8.2, a program created by researchers at the University of Washington [29-33]. The overall amplitude parameters $\mathrm{S}_{0}{ }^{2}$ of all measured samples were set to 0.94 [17].
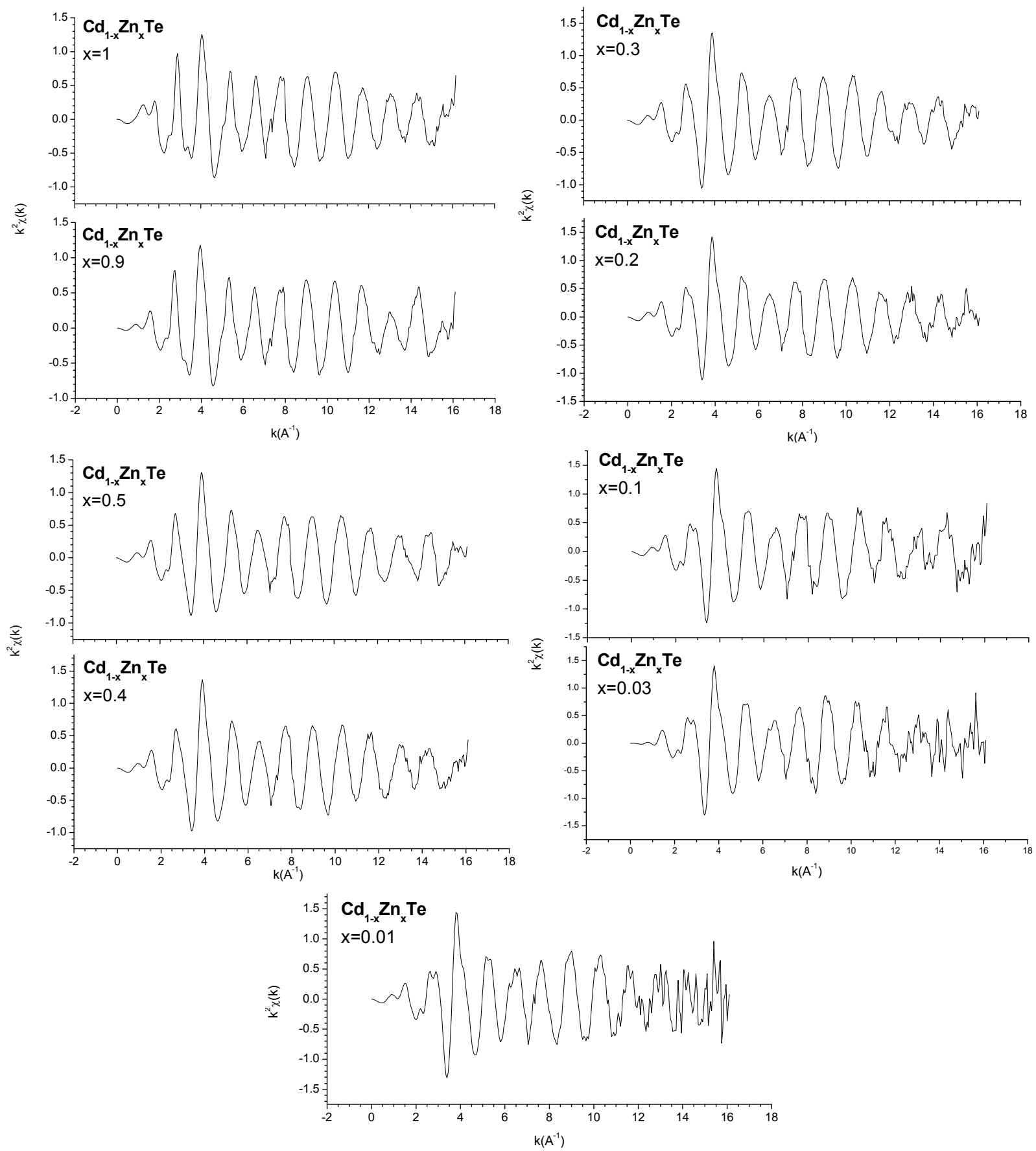

Fig. 1. The $Z n K$-edge oscillation $k^{2} \chi(k)$ for the measured $C d_{1-x} Z n_{x} T$ e samples with $x=0.01, .003,0.10,0.20,0.30,0.40$, $0.50,0.90$ and 1.00 . 

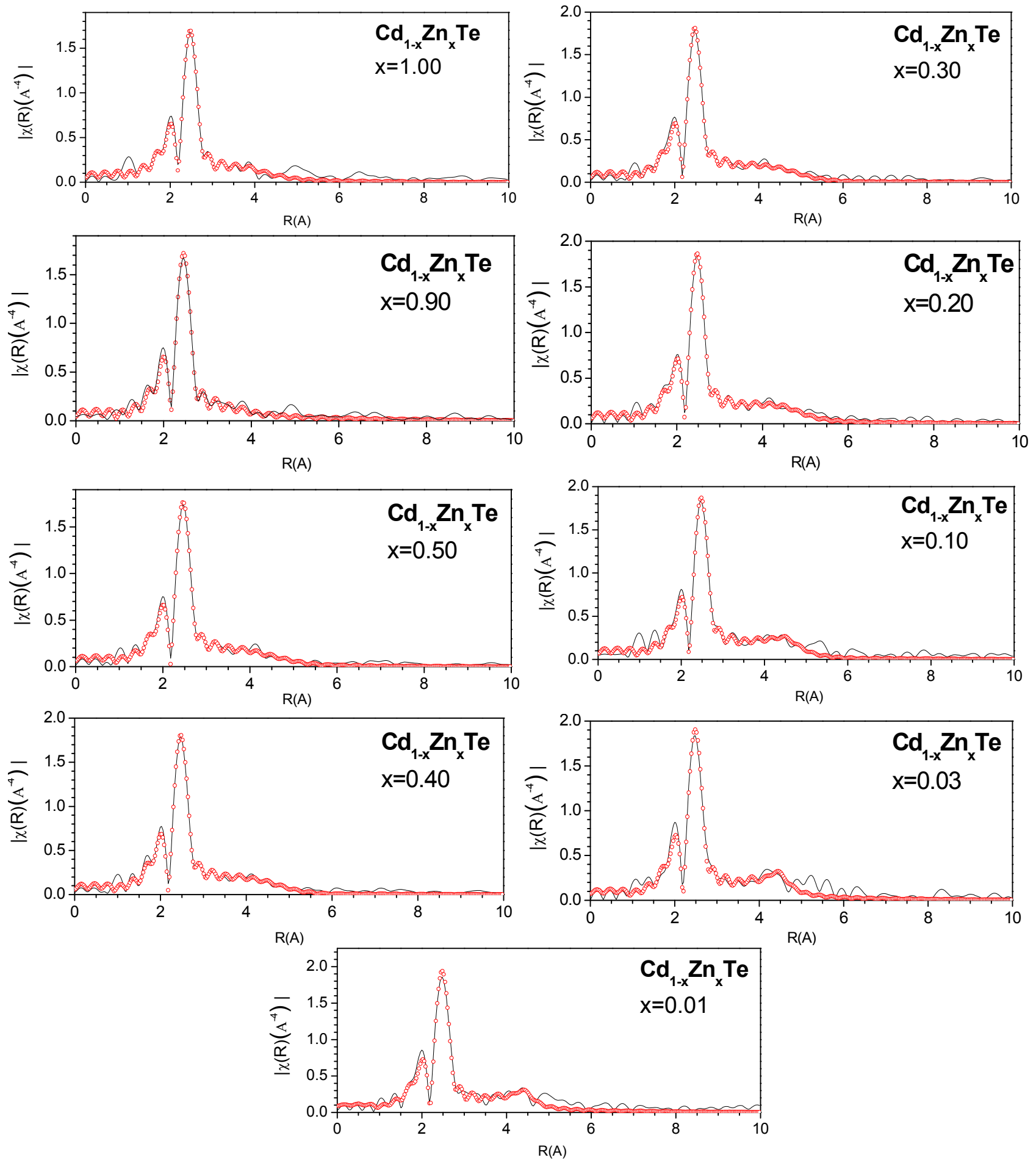

Fig. 2. Black solid lines show the magnitude of the Fourier transforms of measured samples and the red circled line represented the results of fitting. 
The EXAFS technique was employed to probe the local atomic structure on the $\mathrm{Zn}$ atoms for the $\mathrm{Cd}_{1-\mathrm{x}} \mathrm{Zn}_{\mathrm{x}} \mathrm{Te}$ systems with $x=0.01,0.03,0.10,0.20,0.30,0.40,0.500 .90$ and 1.00 covering the whole $x$ range. As the first result we observed that over the whole range of $x$-values the signal of the first $(n n)$ shell in the Fourier transform of the absorption spectra (Fig. 2) does not change its character significantly with varying Zn content, while the higher-order neighbor peaks (above $R \approx 4 \AA$ ) are not so pronounced and are strongly smeared out for higher- $x$ values. With the first neighbor peak being well defined in the $\mathrm{Zn}$ absorption, we have extracted the $\mathrm{Zn}-\mathrm{Te}$ bond length from the $\mathrm{Zn}$ data which is listed in Table. 1. The concentration dependence of this bond length is shown in Fig. 3. For comparison the data extracted from the $K$-edge study on $\mathrm{Cd}$ by V. Koteski [43] as well as from X-ray diffraction in accordance with the virtual crystal approximation (VCA model, Vegard's law) are given [44](Solid line in Figure 3). The results imply that the local atomic structure is distorted and Fig. 3 exhibits a bimodal structure, showing a tendency to retain the values of pure compounds than to the average distance measured by X-ray diffraction.

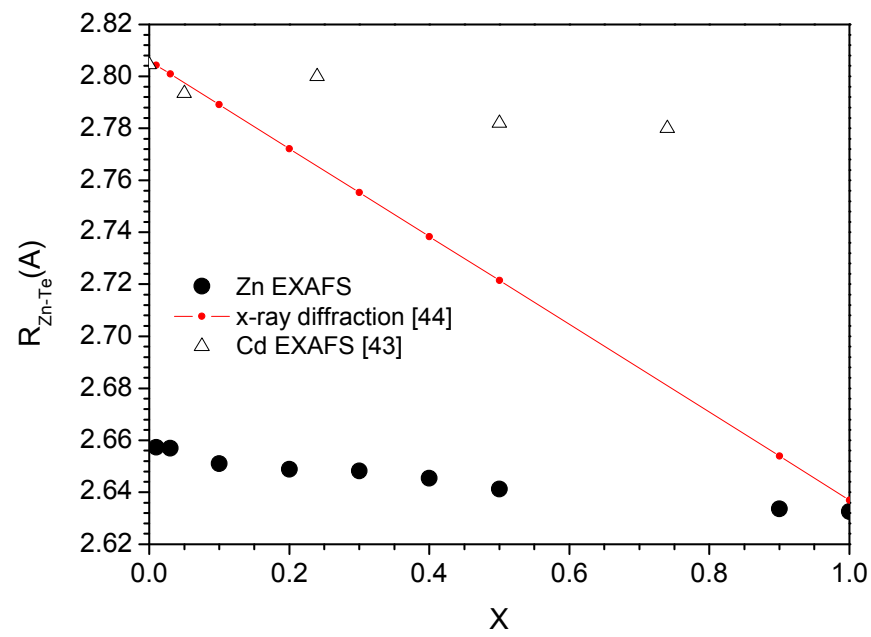

Fig. 3. Local bond length of Cd-Te (triangles) given by Ref. 43 and $\mathrm{Zn}$-Te (circles). The local bond lengths deviate strongly from Vegard's law (VCA) as given by x-ray diffraction data [44].

Table. 1. The results of the EXAFS data fits for first coordination shell atom around Zn atom.

\begin{tabular}{ccccc}
\hline \hline $\mathrm{Cd}_{1-\mathrm{x}} \mathrm{Zn}_{\mathrm{x}} \mathrm{Te}$ & $\mathrm{S}_{0}{ }^{2}$ & $\mathrm{~N}$ & $\mathrm{R}(\AA)$ & $\sigma^{2}$ \\
\hline $\mathrm{x}=0.01$ & 0.94 & 3.659 & 2.65728 & 0.00617 \\
$\mathrm{x}=0.03$ & 0.94 & 3.633 & 2.65698 & 0.00625 \\
$\mathrm{x}=0.10$ & 0.94 & 3.598 & 2.65103 & 0.00633 \\
$\mathrm{x}=0.20$ & 0.94 & 3.490 & 2.64887 & 0.00607 \\
$\mathrm{x}=0.30$ & 0.94 & 3.444 & 2.64822 & 0.00618 \\
$\mathrm{x}=0.40$ & 0.94 & 3.357 & 2.64534 & 0.00606 \\
$\mathrm{x}=0.50$ & 0.94 & 3.250 & 2.64125 & 0.00602 \\
$\mathrm{x}=0.90$ & 0.94 & 2.795 & 2.63359 & 0.00521 \\
$\mathrm{x}=1.00$ & 0.94 & 3.132 & 2.63256 & 0.00579 \\
\hline \hline
\end{tabular}




\subsection{Raman scattering}

Micro-Raman imaging is an intensity contrast derived from a material's intrinsic vibrational spectroscopy signature, which is highly sensitive to the composition, structure of the material, and its local chemical environment. It is a nondestructive and noncontact technique, which needs little or no material preparation, hence making it widely applicable for material research. Here, Raman spectroscopy was used to analysis and understanding the nature of Te precipitates in $\mathrm{Cd}_{1-\mathrm{x}} \mathrm{Zn}_{\mathrm{x}} \mathrm{Te}$ crystals.

Tellurium crystallizes with space group $\mathrm{D}_{3}^{4}$ (or $\mathrm{D}_{3}{ }^{5}$ ) having three atoms per unit cell arranged helically about c axis. The symmetries of the optical phonons at the center of the Brillouin zone are one Raman active $A_{1}$ singlet, one infraredactive (extraordinary ray) $\mathrm{A}_{2}$ singlet, and two Raman and infrared-active (ordinary ray) E doublets [40].

Our Raman measurement was employed to measure $\mathrm{Cd}_{1-\mathrm{x}} \mathrm{Zn}_{\mathrm{x}}$ Te alloys at National Taiwan University under room temperature. As Fig. 4 shown clearly, the spectra are different from the first time we measured (not shown here) [34]. The additional peak around $121 \mathrm{~cm}^{-1}$ and $141 \mathrm{~cm}^{-1}$ can be attributed to the surface Te precipitates, and the TO mode of CdTe, respectively. The broad peak centered at $\sim 160 \mathrm{~cm}^{-1}$ in the Raman shift spectra can be considered as the longitudinal optical (LO) mode of CdTe and it is consistence with the result we measured at first time. The scattering cross section for the peak at $\sim 121 \mathrm{~cm}^{-1}$ has been observed as indeed greater than the one for CdTe Raman signals. Besides, owing to the Te precipitates, most $532 \mathrm{~nm}$ laser was absorbed at the surface on the sample and was hard to penetrate into the under layer. Moreover, according to Ref. 45, the penetrating depth of 532nm laser for CdTe and ZnTe were $0.02 \mathrm{~m}$ and $0.04 \mathrm{~m}$, respectively. It is the reason that under $532 \mathrm{~nm}$ laser excitation the signal of ZnTe is more obvious than CdTe in the Raman spectra, which can be seen clearly in Fig. 5 and $6 .$.

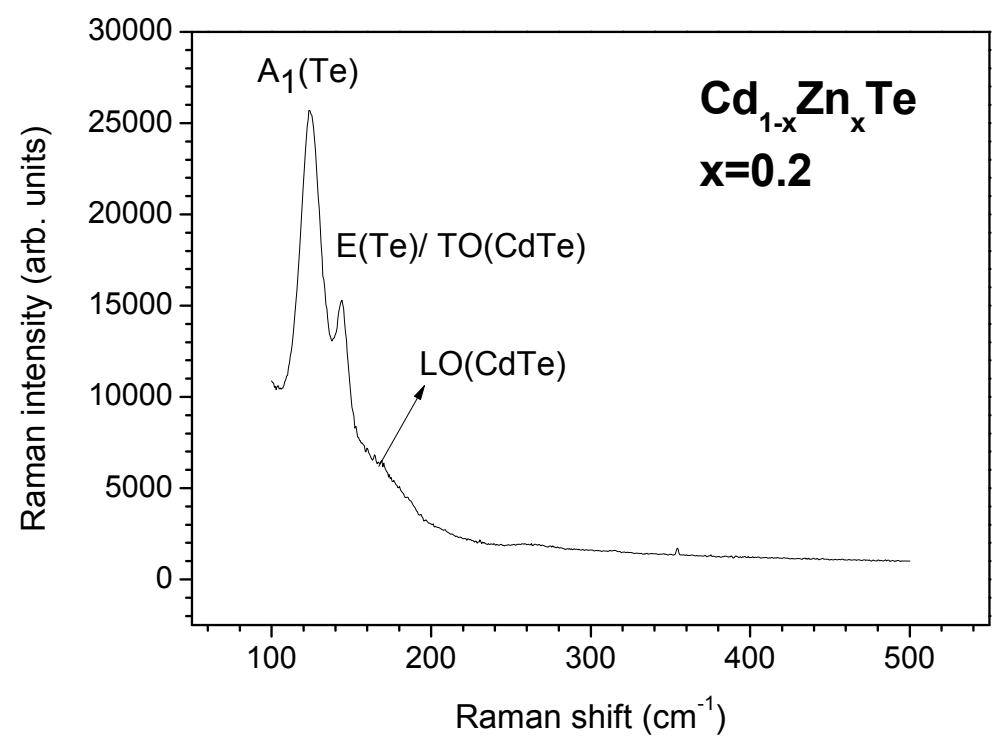

Fig. 4. Micro-Raman spectrum of $C d_{1-x} Z n_{x}$ Te with $x=0.2$. The Raman modes of Te precipitates occur at $121\left(A_{1}\right)$ and $141(E) \mathrm{cm}^{-1}$, respectively.

Samantha A. Hawkins et al. [40] have been reported the damage that occurs during characterization of the CdZnTe surface by a laser during Raman spectroscopy, even at minimal laser powers. Their Raman studies for CdZnTe crystal surfaces have shown that the localized surface heating from tightly focused, low-powered lasers results in areas of higher Te concentration on the CdZnTe surface [40]. This type of laser damage on the surface resulted in decreased detector performance which was most likely due to increased leakage current caused by areas of higher Te concentration. Here, Raman spectroscopy was used to characterize the extent of damage to the different composition of $\mathrm{Cd}_{1-\mathrm{x}} \mathrm{Zn}_{\mathrm{x}} \mathrm{Te}$ crystal surface (with $\mathrm{x}=0.10,0.30,0.50,0.90$ and 1.00 ) following exposure to laser at room temperature.

Fig. 5 shows the Raman spectra recorded at different laser exposure time on $\mathrm{Cd}_{1-\mathrm{x}} \mathrm{Zn}_{\mathrm{x}} \mathrm{Te}$ with $\mathrm{x}=0.90$. The spectra show a range from initial exposure to $3600 \mathrm{~s}$ of laser exposure and the laser power used was $0.050 \mathrm{~mW}$. Owing to the high doping concentration of $\mathrm{Zn}$, the peak at about $210 \mathrm{~cm}^{-1}$ attributed to the LO phonon mode of ZnTe can be observed clearly. As Fig. 5 shown, in the beginning of exposure to the laser, there is only ZnTe peak can be seen in the Raman shift spectra. Subsequently the growth of the Te $A_{1}$ phonon mode appears at $132 \mathrm{~cm}^{-1}$ which shows a little blue shift with 
respect to the result we described above. For a longer exposure time to the laser, a weak peak which can be assigned to the Te E phonon mode becomes more intense in the Raman spectra. A similar result can be obtained in Fig. 6 on ZnTe crystal surface. It is worth noting that with increasing of the exposure time the intensity of the Te phonon mode grows up and the decrease of the ZnTe phonon mode can be seen clearly in Fig. 6(b). As a result, this observation might be suggest that the ZnTe bonding was broken due to the highly focused laser which causes a localized surface heating effect and the free Te atoms migrate to the heated areas. Lucile C. Teague et al. [42] had been used AFM and Raman to study the localized surface damage in the areas exposed to the Raman laser beam on $\mathrm{Cd}_{1-\mathrm{x}} \mathrm{Zn}_{\mathrm{x}} \mathrm{Te}$ crystal surface with $\mathrm{x}=0.10$. They found that (1) localized surface heating causes $\mathrm{Cd}$ material to be evaporated from the surface, which in some cases causes voids in the surface, and (2) free Te atoms are migrating to these heated areas. Here, in the case of highly $\mathrm{Zn}$ doping CdZnTe crystals, we suggest that the ZnTe bond were broken by laser exposing and then free Te atoms are migrating to these heated areas which cause Te precipitate.

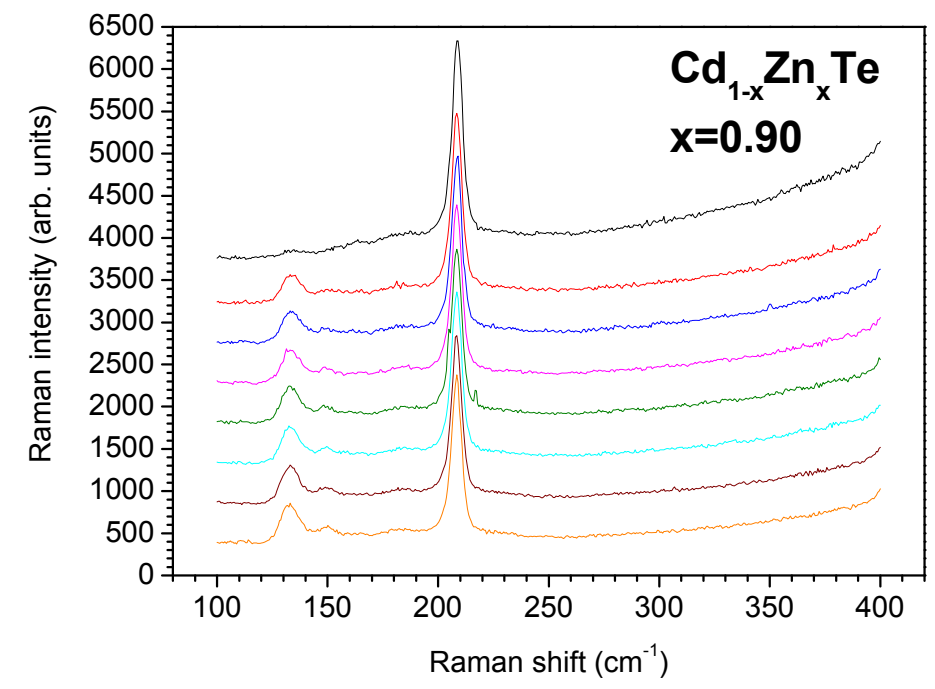

Fig. 5 Raman spectra collected versus laser exposure time on $C d_{1-x} Z n_{x} T e$ with $x=0.9$. The spectra show a range from initial exposure to $3600 \mathrm{~s}$ of laser exposure. The laser power used was $0.05 \mathrm{~mW}$.

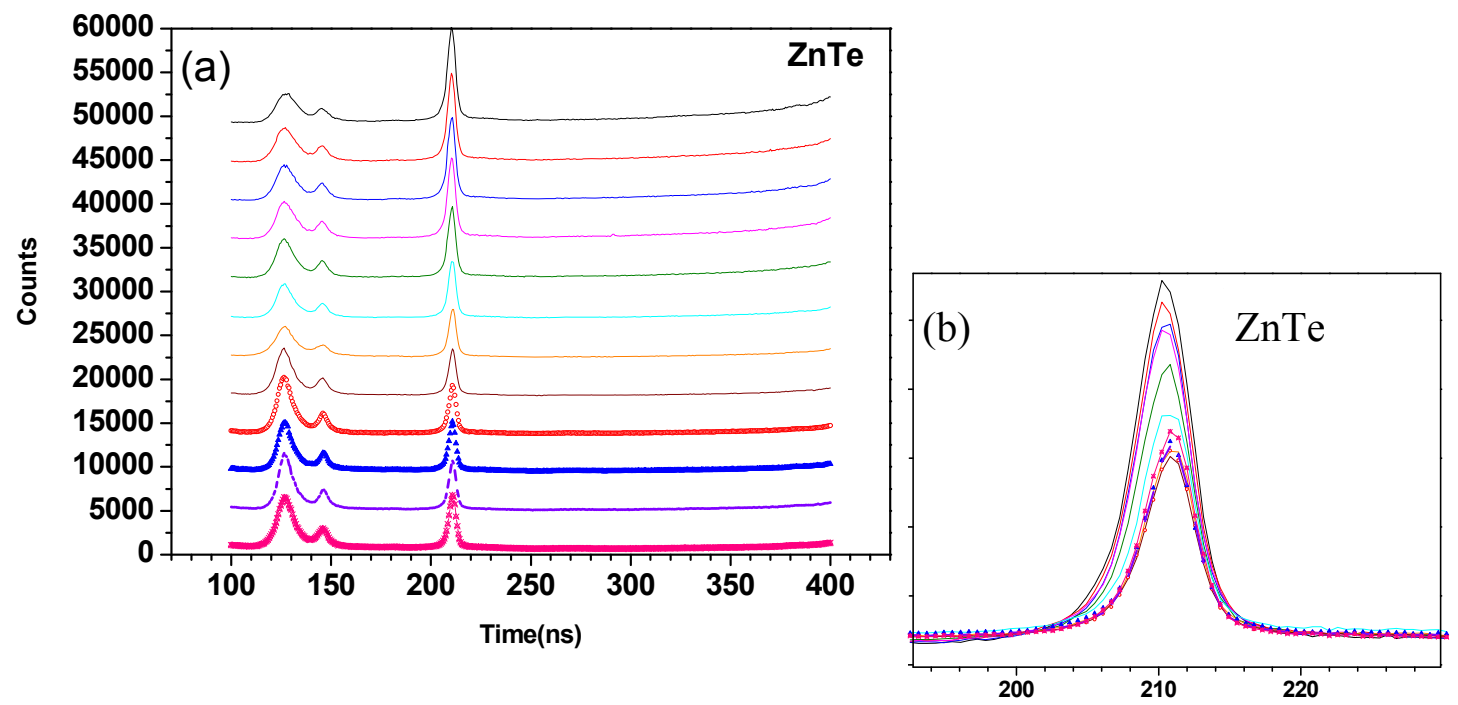

Fig. 6. (a) Raman spectra collected versus laser exposure time on ZnTe. The spectra show a range from initial exposure to $3600 \mathrm{~s}$ of laser exposure. The laser power used was $1.5 \mathrm{~mW}$. (b) The intensity of ZnTe LO phonon mode decreases with increasing the laser exposure time. 


\subsection{Tender X-ray absorption}

Fig. 7 11 show the tender X-ray absorption measurements on $\mathrm{Cd}$ and Te L-edge, respectively. These experiments were operated in X-ray fluorescence yield mode at beamline 16A of the National Synchrotron Radiation Research Center (NSRRC) in Hsinchu, Taiwan. Owing to the lack of the reference, this part of experimental data needs to do penetrating analysis in the future. Here, we just list the results of measurements.

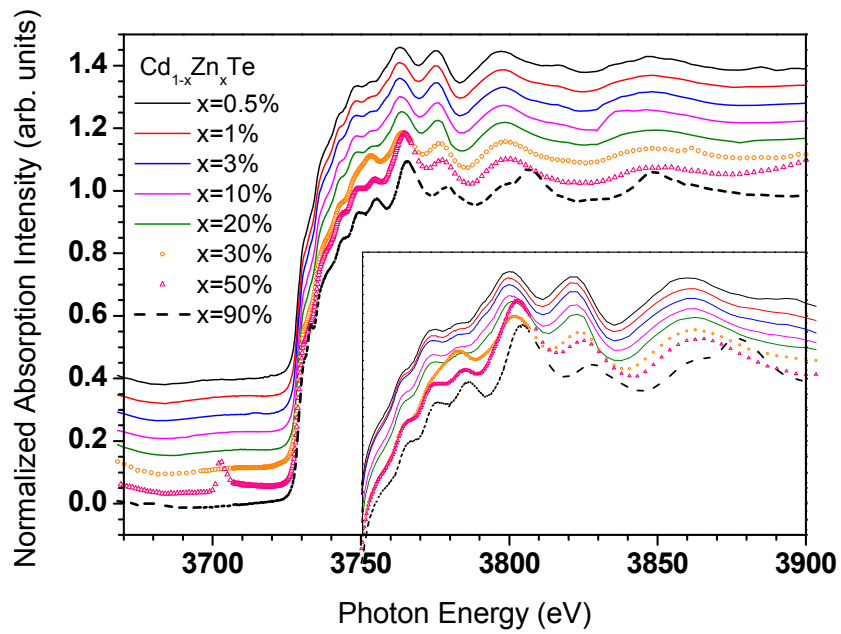

Fig. 7. $C d L_{2}$-edge of $C d_{1-x} Z n_{x} T e$ with $x=0.005,0.01,0.03,0.1,0.2,0.3,0.5$ and 0.9, respectively.

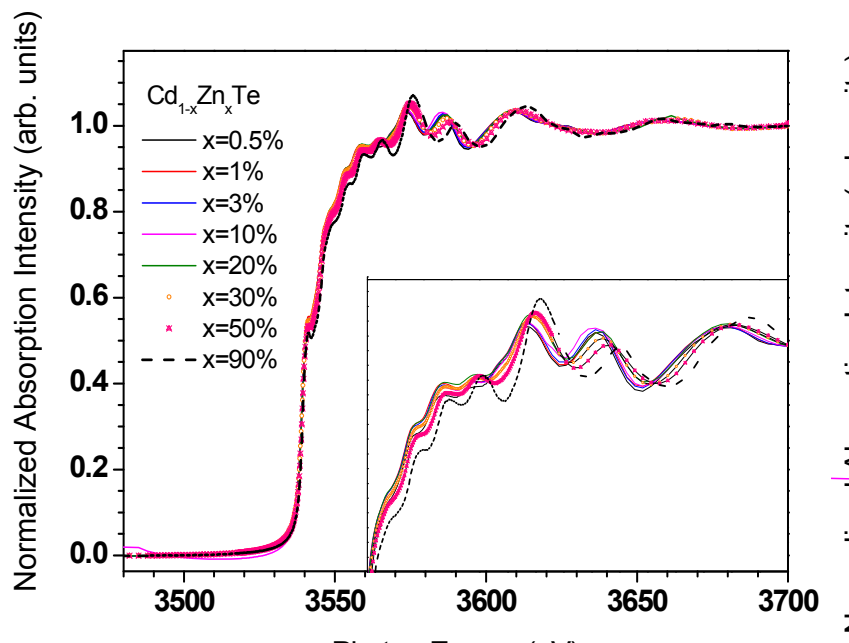

Photon Energy (eV)

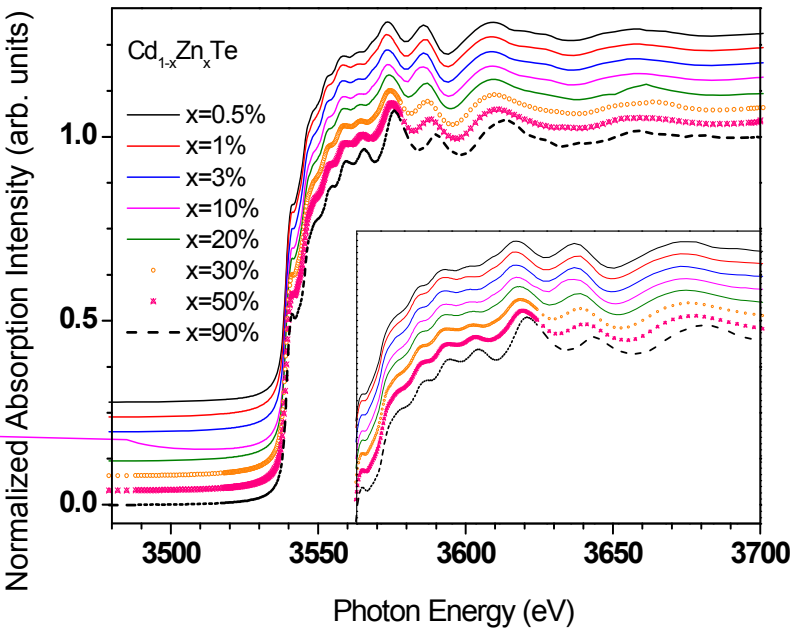

Photon Energy (eV)

Fig. 8. (a) $C d L_{3}$-edge of $C d_{1-x} Z n_{x} T e$ with $x=0.005,0.01,0.03,0.1,0.2,0.3,0.5$ and 0.9 , respectively. (b) The same figure shifted by y axis. 


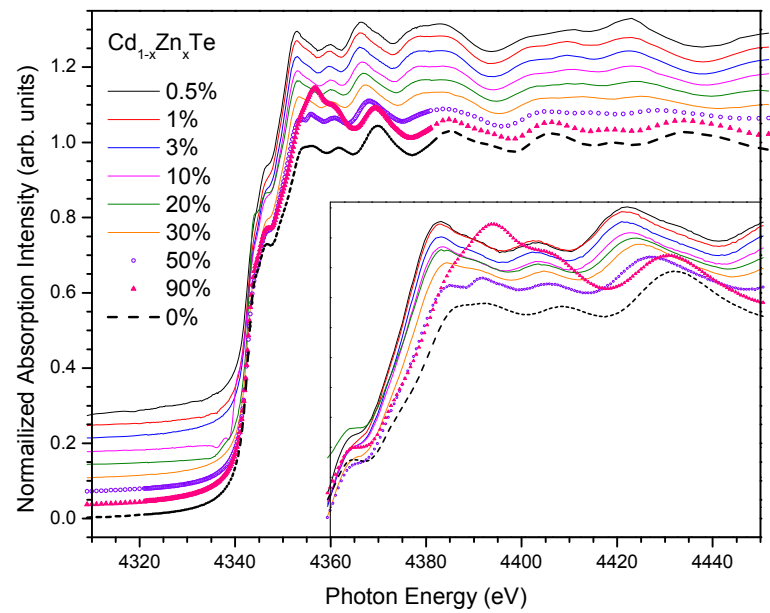

Fig. 9. Te $L_{3}$-edge of $C d_{1-x} Z n_{x}$ Te with $x=0.005,0.01,0.03,0.1,0.2,0.3,0.5,0.9$ and 1.0, respectively.

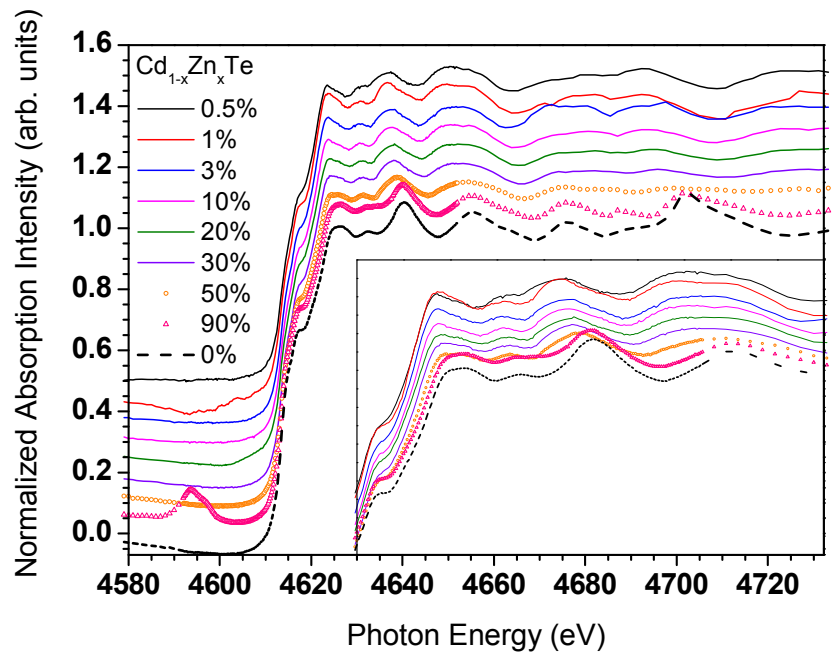

Fig. 10. Te $L_{2}$-edge of $C d_{1-x} Z n_{x}$ Te with $x=0.005,0.01,0.03,0.1,0.2,0.3,0.5,0.9$ and 1.0, respectively.
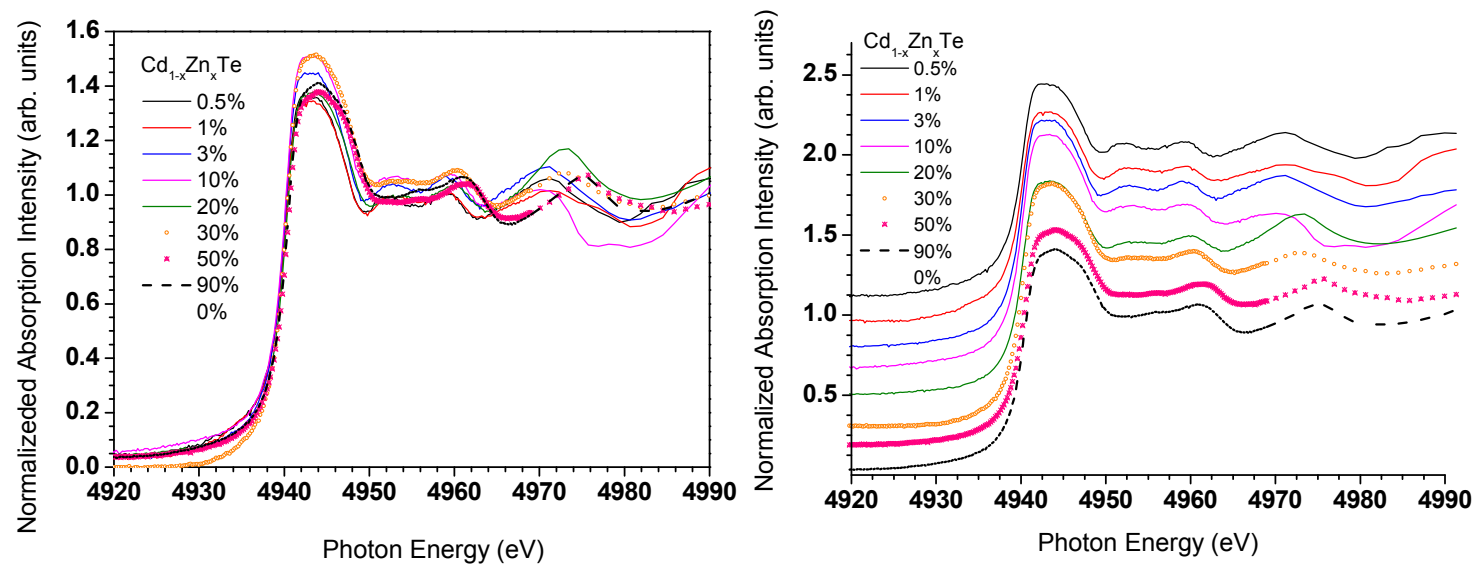

Fig. 11. (a) Te $L_{1}$-edge of $C d_{1-x} Z n_{x} T e$ with $x=0.005,0.01,0.03,0.1,0.2,0.3,0.5,0.9$ and 1.0, respectively. (b) The same figure shifted by y axis. 


\section{CONCLUSION}

The alloy $\mathrm{Cd}_{1-\mathrm{x}} \mathrm{Zn}_{\mathrm{x}} \mathrm{Te}$ can ideally be regarded as a CdTe crystal with $\mathrm{Zn}$ atoms randomly substituted for a fraction $\mathrm{x}$ of the $\mathrm{Cd}$ atoms. The difference in the lattice constants of CdTe and ZnTe implies that this substitution is accompanied by some change in the average unit cell dimension. It is usually assumed that the resulting lattice constant is a linear interpolation between the two constituents, but EXAFS measurements have shown a bimodal distribution of bond lengths, suggesting distortion of the Te sub-lattice, so that the linear interpolation is true only in an approximate sense.

Low-temperature Raman scattering had been employed to study anomalous character of the phonon mode in $\mathrm{Cd}_{1}$. ${ }_{x} \mathrm{Zn}_{\mathrm{x}} \mathrm{Te}$ crystals several years ago. The vibrational modes of $\mathrm{Cd}_{1-\mathrm{x}} \mathrm{Zn}_{\mathrm{x}} \mathrm{Te}$, as observed by infrared or Raman scattering measurements, are not a simple interpolation between those of its constituents. Rather than a single TO and a single LO mode, two of each type of mode are observed, one being termed "CdTe-like" and the other, "ZnTe-like." This behavior is typical for ternary semiconductor compounds, but $\mathrm{Cd}_{1-\mathrm{x}} \mathrm{Zn}_{\mathrm{x}} \mathrm{Te}$ has the unique property that the frequencies of both TO modes increase with $\mathrm{x}$. In all similar alloys one TO frequency increases while the other decreases with $\mathrm{x}$.

$\mathrm{Cd}_{1-\mathrm{x}} \mathrm{Zn}_{\mathrm{x}} \mathrm{Te}$ crystals have been measured again by Raman scattering at room temperature. It is strange that the Raman signals are different from the last measurement at low temperature, especially two observed peaks at about 125 and 145 $\mathrm{cm}^{-1}$ which can be assigned to Te $\mathrm{A}_{1}$ and $\mathrm{E}$ phonon mode, respectively. The induced damage on the crystal surfaces by Raman laser has been confirmed. Two peaks in the Raman shift spectra both grow with increased laser exposure and it is likely that the growth of both peaks is due to Te secondary phase enrichment on the surface. This may be the reason that we observed different Raman signals at different time's measurements.

\section{REFERENCES}

[1] P.W. Kruse In: R.K. Willardson and A.C. Beer, Editors, Semiconductors and Semimetals, 18, Academic Press, New York (1981).

[2] T.E. Schlesinger, J.E. Toney, H. Yoon, E.Y. Lee, B.A. Brunett, L. Franks and R.B. James, Mater. Sci. Eng. Rep., 32 103 (2001).

[3] A.S. Alikhanian, V.N. Guskov, A.M. Natarovsky, J.H. Greenberg, M. Fiederle and K.W. Benz, J. Crystal Growth, 24073 (2002).

[4] B.M. Basol, V.K. Kapur and M.L. Ferris, J. Appl. Phys., 661816 (1989).

[5] K.L. Chopra, P.D. Paulson and V. Dutta, Sol. Cells, 12 69(2004).

[6] A. Partovi, A.M. Glass, D.H. Olson, G.J. Zydzik, K.T. Short, R.D. Feldman and R.F. Austin, Appl. Phys. Lett., 59 $1832(1991)$.

[7] L. Turjanska, P. Höschl, E. Belas, R. Grill, J. Franc and P. Moravec, Nucl. Instr. and Meth. A, 45890 (2001).

[8] G. Li, X. Zhang, H. Hua and W. Jie, J. Electron. Mater., 341215 (2005).

[9] R. Triboulet, in: H.J. Scheel, T. Fukuda (Eds.), Crystal Growth Technology, 373 (2003).

[11] G. Li, W. Jie, H. Hua and Zhi Gu, Prog. Cryst. Growth Charact. 4685 (2003).

[12] Guoqiang Li, Shao-Ju Shih, Yizhong Huang, Tao Wang and Wanqi Jie, J. Crystal Growth, 31185 (2008).

[13] T.E. Schlesinger, J.E. Toney, H. Yoon, E.Y. Lee, B.A. Brunett, L. Franks, and R.B. James, Mater. Sci. Eng. R, 32 103 (2001).

[14] B.A. Brunett, J.M. Van Scyoc, N.R. Hilton, J.C. Lund,R.B. James, and T.E. Schlesinger, IEEE Trans. Nucl. Sci., 46237 (1999).

[15] B.A. Brunett, J.M. Van Scyoc, T.E. Schlesinger, and R.B. James, Nucl. Instrum. Methods A, 45876 (2001).

[16] P.N. Luke, M. Amman, and J.S. Lee, IEEE Trans. Nucl. Sci. 511199 (2004).

[17] M.C. Duff, D.B. Hunter, A. Burger, M. Groza, V. Buliga, and D.R. Black, Appl. Surf. Sci., 2542889 (2008).

[18] A. Burger, K. Chattopadhyay, H. Chen, X. Ma, J.-O. Ndap, M. Schieber, T.E. Schlesinger, H.W. Yao, J. Erickson, and R.B. James, Nucl. Instrum. Methods A, 448586 (2000).

[19] A.E. Bolotnikov, G.S. Camarda, G.A. Carini, Y. Cui, L. Li, and R.B. James, Nucl. Instrum. Methods A, 579125 (2007).

[20] M. Schieber, R.B. James, H. Hermon, A. Vilensky, I. Baydjanov, M. Goorsky, T. Lam, E. Meerson, H.W. Yao, J. Erickson, E. Cross, A. Burger, J.O. Ndap, G. Wright, and M. Fiederle, J. Cryst. Growth, 231235 (2001).

[21] C.M. Greaves, B.A. Brunett, J.M. Van Scyoc, T.E. Schlesinger, and R.B. James, Nucl. Instrum. Methods A, 45896 (2001).

[22] M. Sridharan, Sa.K. Narayandass, D. Mangalaraj, and H. Chul Lee, Vacuum, 70511 (2003). 
[23] T. Wang, W. Jie, J. Zhang, G. Yang, D. Zeng, Y. Xu, S. Ma, H. Hua, and K. He, J. Cryst. Growth, 304313 (2007).

[24] D. Zeng, W. Jie, G. Zha, T. Wang, and G. Yang, J. Cryst. Growth, 30550 (2007).

[25] T. Wang, W. Jie, and D. Zeng, Mater. Sci. Eng. A-Struct., 472227 (2008).

[26] A.S. Pine and G. Dresselhaus, Phys. Rev. B, 4356 (1971).

[27] P. Rudolph and M. Mu" hlberg, Mater. Sci. Eng. B, 168 (1993).

[28] M. Newville, P. Livins, Y. Yacoby, J.J. Rehr, and E.A. Stern, Phys. Rev. B, 4714126 (1993).

[29] J. Mustre de Leon, J.J. Rehr, S.I. Zabinsky, and R.C. Albers, Phys. Rev. B, 444146 (1991).

[30] J.J. Rehr and R.C. Albers, Phys. Rev. B, 418139 (1990).

[31] J.J. Rehr, J. Mustre de Leon, S.I. Zabinsky, and R.C. Albers, J. Am. Chem. Soc., 1135135 (1991).

[32] J.J. Rehr, S.I. Zabinsky, and R.C. Albers, Phys. Rev. Lett., 693397 (1992).

[33] E.A. Stern, M. Newville, B. Ravel, Y. Yacoby, and D. Haskel, Physica B, 117, 208 (1995).

[34] D. N. Talwar, Z. C. Feng, P, Becla, Phys. Rev. B, 4817064 (1993).

[35] N. Vagelatos, D. Wehe and J. S. King, J. Chem. Phys., 603613 (1974).

[36] J. M. Rowe, R. M. Nicklow, D. L. Price and K. Zanio, Phys. Rev. B., 10671 (1974)

[37] H. Narada and S.Narita, J. Phys. Soc. Jpn., 301628 (1970).

[38] L. K. Vodop'yanov, E. A. Vinogradov, A. M. Blinov and V. A. Rukavishnikov, Fiz. Tverd. Tela (Leningrad), 14 268 (1972).

[39] E. A. Vinogradov and L. K. Vodop'yanov, Fiz. Tverd. Tela (Leningrad), 173161 (1975).

[40] Samantha A. Hawkins, Eliel Villa-Aleman, Martine C. Duff, Doug B. Hunter, Arnold Burger, Michael Groza, Vladimir Buliga and David R. Black, J. Electron. Mater., 371438 (2008).

[41] A.S. Pine and G. Dresselhaus, Phys. Rev. B, 4356 (1971).

[42] Lucile C. Teague, Samantha A. Hawkins, Martine C. Duff, Michael Groza, Vladimir Buliga and Arnold Burger, $J$. Electron. Mater. (2009).

[43] V. Koteski, H. Haas, E. Holub-Krappe, N. Ivanovic-and H. -E. Mahnke, Journal of alloys and compounds, 26138 (2004).

[44] Motta, N., Balzarotti, A., Letardi, P., Kisiel, A., Czyzyk, M. T., Zimnal-Starnawska, M. and Podgorny, M., J. Crystal Growth 72205 (1985).

[45] Sadao Adachi, "Optical Constants of Crystalline and Amorphous Semiconductors" (1999). 